\title{
Implementation of battery management module for the microgrid: A case study
}

\author{
Li Han ${ }^{\mathrm{a}}$, Syed Furqan Rafique ${ }^{\mathrm{b}, \mathrm{c}}$, Zhang Jianhua ${ }^{\mathrm{b}}$ \\ ${ }^{a}$ State Grid Corporation Limited, China \\ ${ }^{b}$ North China Electric Power University, Beijing, 102206, China \\ ${ }^{c}$ Goldwind Technology, Boxing $1^{\text {st }}$ Road, Beijing101102, China,
}

\begin{abstract}
An optimal cost effective battery management strategy is developed for Microgrid based on a daily tariff from grid side. A Microgrid is an excellent frame work which gives a decentralized scheme to capitalize diverse renewable resources by cutting down power need of a consumer from the utility grid .Firstly, a daily price pattern of a load area is distributed into different regions for an average consumption of energy profile then the battery charging and discharging scheme is setup based on the availability of the renewable resources and the state of the charge .Real time 10min dispatch information send to Battery PCS through Modbus communication protocol and check the status of all generation and consumption units on graphical user interface developed in C\#/Matlab. This proposed scheme is applied to the Beijing Goldwind Microgrid test bed which consist of Wind ,PV and Vanadium redox flow battery to supply power to a commercial building. The results are showing minimum dependencies on the grid power and utilizing all renewable and battery power at an optimum way.
\end{abstract}

Keywords: Microgrid; real time power dispatch; vanadium redox flow battery; state of charge

\section{Introduction}

Renewable energy application development is the only solution for energy shortage and environmental issues in current growing economies around the globe. As On the distribution side, Microgrid is the best way to fully utilize the benefits of the renewable energy sources and assist consumer to reduce the dependency on the utility grid. It can help to reduce the variability of renewable resources as well as improve the reliability and efficiency of power supply [1]. Researchers are finding new ways to solve the issues related to Microgrid such as coordinated control of all Distributed Generations (DGs) and utility [2], protection schemes (as of bidirectional flow in distribution system) [3] and energy management (optimal use of all resources to improve economic and environmental benefits) [4]. In order to promote the ongoing research in this area usually countries like USA, China, Germany and Canada are granting a lot of investment to develop test beds of Microgrid and facilitate in solving different scenarios on variety of DGs and Energy Storage System (ESS) in Microgrid. In the context of Energy management through Microgrid, a reliable and secure operation must be carried out in order to get the optimal (or near optimal) point of operation such as unit commitment and dispatch for the available DGs to achieve required targets. This task is getting difficult in Islanded mode of Microgrid where the refresh rate must be higher to tackle the sudden changes in renewable generators and load demand [5].

\begin{tabular}{|cl|}
\hline Nomenclature & \\
$P_{w}, P_{S}$ & Power of WT and PV produced \\
$\varphi_{w}$ & Air of water $1.225 \mathrm{~kg} / \mathrm{m}^{3}$ \\
\hline
\end{tabular}

*Manuscript received October 22, 2016; revised January 22, 2017.

Corresponding author. Tel.: +8618811165701; E-mail address:furqanbee@ gmail.com.

doi: $10.12720 /$ sgce.6.1.11-20 


\begin{tabular}{|cl|}
\hline$A_{w}$ & Swept Area \\
$\in_{w} \in_{p v}$ & Combined Efficiency of WT and PV system \\
$C_{p}$ & Coefficient of WT performance \\
$V$ & Wind velocity \\
$g(t), h(t)$ & Wind Probability density function and radiance density function \\
$r(t)$ & Hourly radiation kWh/m ${ }^{2}$ \\
$d_{\text {self }}$ & Self-discharge rate \\
$S_{\text {bat }}$ & Capacity of battery at any time \\
$S_{\text {int }}$ & Initial SOC \\
$\in_{\text {bat }}$ & Efficiency of charge and discharge \\
$C_{n o r m a l}$ & Battery nominal energy \\
$M_{\text {bat }}$ & Maximum battery capacity \\
$p s r c$ & Per sample rate (charge/discharge) coefficient \\
A,b,Aeq, & Matrices and vectors of constraints and limits \\
Beq,Lx,Ux & \\
\hline
\end{tabular}

Battery management system integrated with the renewable sources like wind turbine and solar panel provides much flexible energy management as well as increase the reliability and power quality of Microgrid. several researches [4]-[6], [9]-[11] showed improve power quality in hybrid Wind, solar and battery schemes. Apart from just smoothing the RE effects these BMSs could mitigate frequency fluctuations and transmission losses and provide peak shaving facilitates.

Chen et al [5], presented an smart energy manager using genetic algorithm .Characteristics of PV in different environment conditions are considered and one day ahead foresting of power is proposed and finally multiple economic objectives simplified into single objective function related to battery, load and generation limits. More research need to be done in this EMS as the commercial and industrial profiles for a certain region still not defined which will help to map more exact relationship in objectives related to generation units, battery and cost of Microgrid.

For economical and efficient use of Renewable sources , an optimal sizing method is also an integral part. This optimum sizing method help to provide full use of all PV, Wind and Battery resources with minimum investment cost so that the hybrid system could able to achieve optimum point in term of cost and reliability. This type of study include the system long run cost vs. performance and economic benefit analysis [6]. For designing a Microgrid on a particular location and environment, assessment of optimal sizing is very important for energy management system where as in test bed schemes one could simply consider different scenarios like flexible generating and load unit for extendable quality of a system in future run.

Kansumba [6] designed two control strategies to minimize the daily operation cost of PV, diesel and hybrid system in islanded Microgrid. He used continuous and ON/OFF modes of operation to solve optimization problem in nonlinear cost of diesel generation. Continuous control shows more fuel saving than the ON/OFF mode whereas the later on achieve reduce operating time for generator which ultimately leads to less environmental damage.

A study of probabilistic analysis for an optimum energy management is considered by Nikmehr [7]. An objective function is minimized by imperialistic competitive algorithm and then use Monte Carlo to simulate different scenarios in order to achieve lowest cost using all uncertain sources such as Wind, PV and others like, battery and Microturbine but this method is not feasible as all such methods required a lot of computation time and hence cant applied directly in real time systems.

A real time energy storage management for renewable integration in Microgrid is proposed by Rahbar [8]. According to authors, a finite horizon real time energy management scheduling is constructed and solved to find the minimum cost of energy used from grid by charging /discharging energy storage for a particular horizon subject to constraints for load and battery. A noisy predicted net energy profile is used 
in off line algorithm to devise and online sliding mode scheme. This algorithm shows better result than heuristic and dynamic programming approaches with fast computation time. The main issue with this approach as to know the prior information about net energy profile otherwise the sliding mode algorithm will not give accurate results.

All aforementioned papers discussed about very effective approaches but rather slow convergence speed in real time processing and prior exact data about forecasting of load, wind and PV which are very difficult to achieve and also used much processing time and cost for a normal customer with small level Microgrid. In this paper, a real time energy management system is developed using a daily price information from the main grid and state of charge of battery without considering of load and renewable sources fluctuation as the main objective here is to minimize the dependency on main grid and fully utilization of Wind, PV power while charging the battery on off-peak time and discharging on peak time according to load and price trend. Software is developed to check the performance and later on it will be available for commercial usage in the market as this is the testing phase of this project.

The Microgrid test bed is used in this paper to check the proposed algorithm and verified the result by running it 24 hour in a test environment. The paper arranged are as follows, Section 2 describe the modelling of each energy source Section 3 describe the state of charge and time based scheduling of battery and Section 4 shows the simulation and real time data values finally Section 5 is the conclusion.

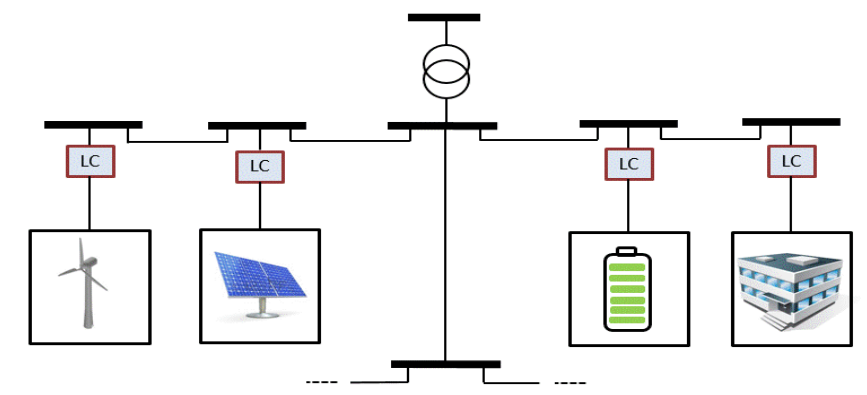

Fig. 1. System topology of gold wind test bed.

\section{System Configuration}

\subsection{The microgrid structure}

A demonstration Microgrid test bed is setup in Goldwind Microgrid facility, Beijing ,the system mainly consist of un dispatch able sources such as wind turbine, Photovoltaic panels and dispatch able sources as vanadium redox flow battery which are used to provide power to a section B office building in the site of Goldwind. A $10 \mathrm{kV}$ bus on the top in Fig. 1 is connected to a main utility grid and a radial distribution level Microgrid whereas $400 \mathrm{~V}$ bus is connected to all sources including office building load.

\subsection{Modelling of wind power generation system}

Wind energy convert a kinetic energy of moving air into mechanical then electrical form of energy. The power output $P_{w}$ through an interval $t$ can be shown as

$$
P_{w}=\frac{1}{2} \varphi_{w} A_{w} \in_{w} C_{p} \int_{t 0}^{t} V^{3} g(t) d t
$$

Table 1. WT parameters

\begin{tabular}{ll}
\multicolumn{2}{c}{ Parameter of WT } \\
\hline Rated Voltage & $690 \mathrm{~V}$ \\
Rated Power & $2500 \mathrm{~kW}$ \\
Cut in wind speed & $3 \mathrm{~m} / \mathrm{s}$ \\
Rated wind speed & $9.3 \mathrm{~m} / \mathrm{s}$ \\
Rotor Diameter & $121 \mathrm{~m}$ \\
\hline
\end{tabular}


The wind power generation system is shown in Fig. 2. Was modeled on 2.5MW GW121/2500 permanent magnet direct drive wind turbine with a $80 \mathrm{~m}$ tower located in Goldwind Technology Park (Yizhuang) Beijing, china. The details parameter and characteristic info are mentioned in Table 1 and also available on website of Goldwind.

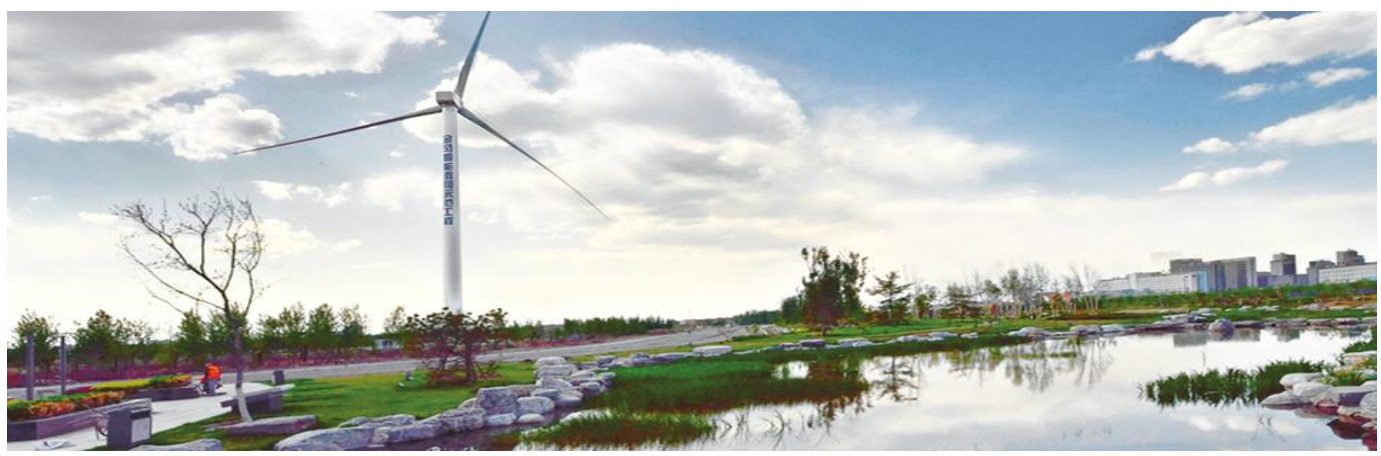

Fig. 2. Goldwind 2.5MW WT at Beijing.

\subsection{Modelling of $P V$ power generation system}

Solar power is harvested through a poly silicon cell which convert it to electricity through photovoltaic reaction. The power rating of cell Ps shows the standard test condition of cell at a temperature around 25 degree Celsius and irradiance of 1000W/m2 in Fig. 3 .

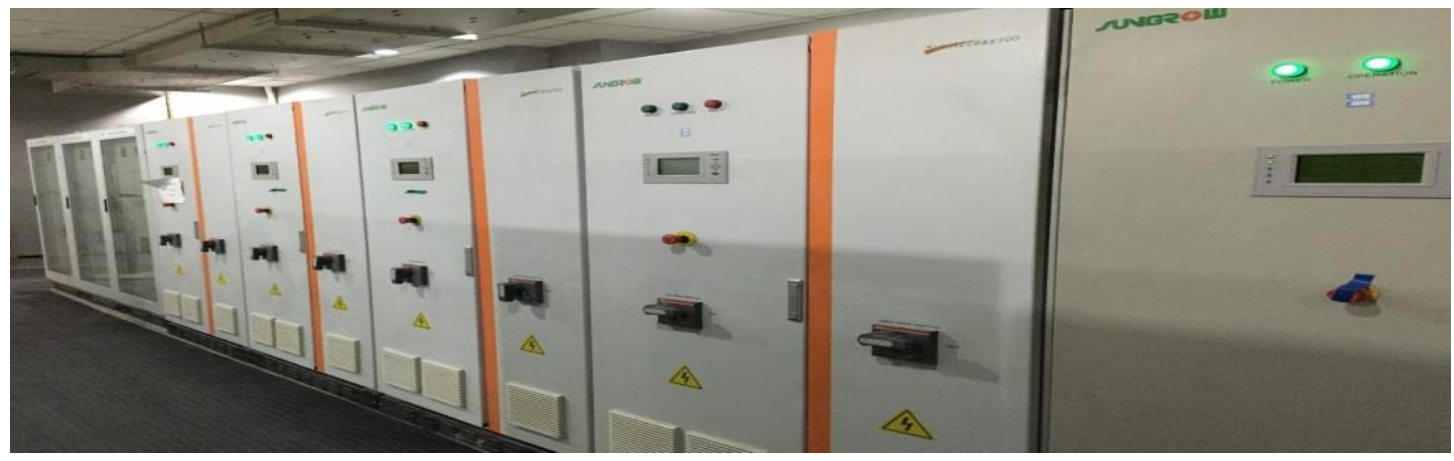

Fig. 3. PV panels on the top of office Building and PCS.

$$
P_{s}=A_{p v} \in_{p v} \int_{t 0}^{t} r(t) h(t) d t
$$

PV power generation was modeled using the historical information available in Goldwind Microgrid research department in Beijing. This system have total two operational PCS available at the time of conducting this research and each of these are $200 \mathrm{~kW}$ used in parallel making in $400 \mathrm{~kW}$ at rated power. The historical power of each of these PV sets are shown in Fig. 4.

\subsection{Energy storage system}

The energy storage system Fig. 4 dynamics can be modelled as a state of charge function which is a first order difference equation in discrete time domain (3).

$$
S_{k}=\left(1-d_{\text {self }}\right) S_{\text {int }}-t_{s} \in_{\text {bat }} / C_{\text {normal }} \sum_{l=k}^{k} P_{\text {bat }_{k}}
$$

where $\mathrm{k}$ is the sample time and $\mathrm{S}_{\mathrm{int}}$ is the initial $\mathrm{SOC}$ at the start of each iteration. Vanadium redox flow battery of $200 \mathrm{kw} / 800 \mathrm{kwh}$ is chosen for this particular energy management system. The net efficiency of 
this kind of battery is high as $85 \%$ and cell voltage is around $1.4-1.6 \mathrm{~V}$ in Table 2 . It consist of 10 cell stacks of $20 \mathrm{~kW}$ connected to $400 \mathrm{~V}$ bus.
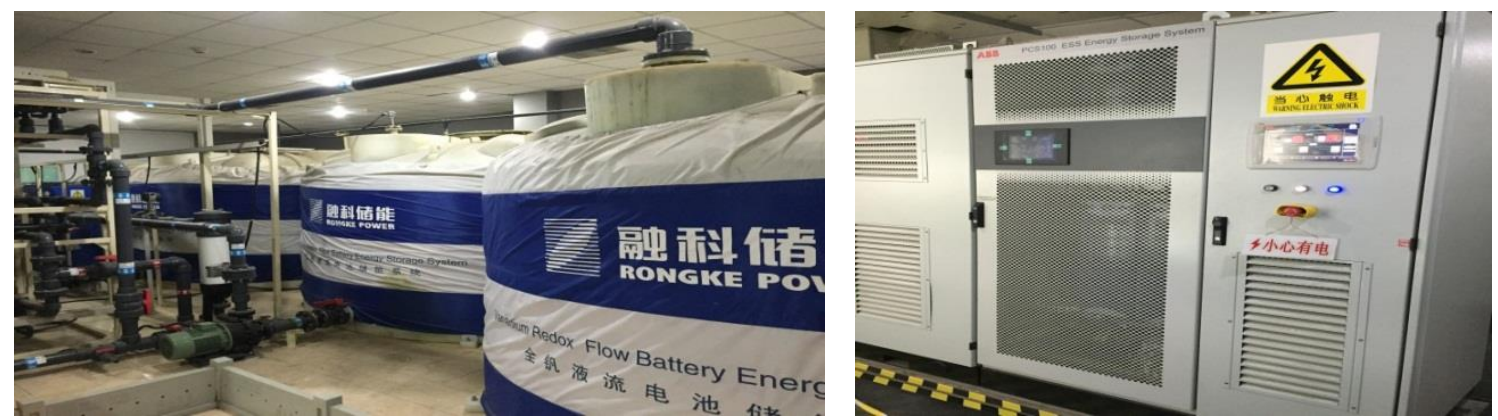

Fig. 4. VRB (left) and the PCS (right) installed in the test facility.

Table 2. Battery parameters

\subsection{Exchange cost}

\begin{tabular}{lc}
\multicolumn{2}{c}{ Parameter of Energy Storage System } \\
\hline Power & $200 \mathrm{~kW}$ \\
Capacity & $800 \mathrm{kWh}$ \\
Voltage range & DC 250-388V \\
Rated Current & DC 640A \\
Ambient temperature & $5-35 \mathrm{c}$ \\
\hline
\end{tabular}

The cost of selling power to local grid is fixed about $0.68 \mathrm{Yuan} / \mathrm{kWh}$ while the cost of buying power is dynamic throughout the day based on the peak, mid and valley time period as shown in Fig 5. The day is divided into three sections 23:00-7:00 is off peak time, 7:00-10:00, 15:00-18:00 are the mid peak time and 10:00-14:00, 18:00-21:00 are peak times.

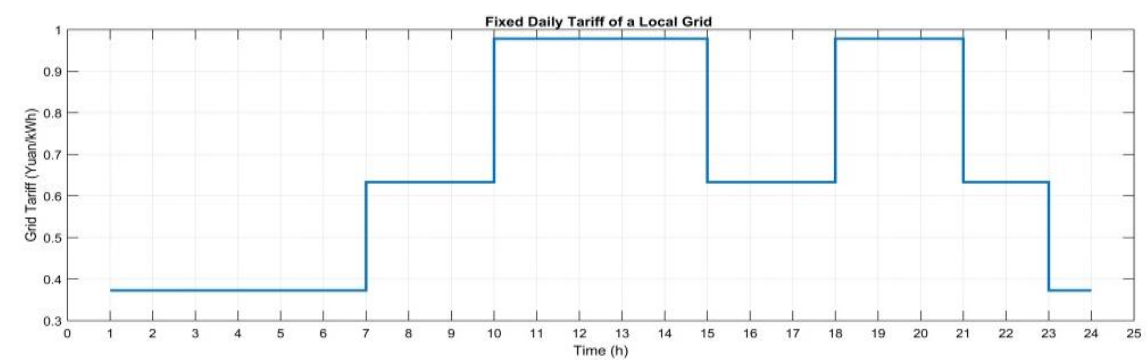

Fig. 5. Electricity buying price for a day.

\section{Proposed Smart Battery Management Module}

\subsection{Site historical data}

We consider the power system comprises on a main grid, a Microgrid and a total load demand as this Microgrid model always work in grid connected so the main elements are: renewable sources, battery system and total load demand. All the historical typical day power output in different seasons are mentioned in from Wind and PV are mentioned in Fig. 3, Fig. 4, Fig. 5.

\subsection{Control formation}

Let's donated the energy discharge (charge) and from (to) the battery at $m$ th interval is $\mathrm{D}_{\mathrm{m}}$ and $\mathrm{C}_{\mathrm{m}}$.Due to the influence of tariff structure it is mandatory to develop the optimization of battery charging and discharging at multiple time step but the ESS economics is fairly complex due to the fact that tariff is less inclined towards the energy charges and more towards the demand charges hence the control and timing of chargeable peak is more important to tackle [5]. A 10min refresh rate for triggering the EMS 
and energy stored used as decision variable.

1. ESS is charging $\left(\mathrm{P}_{\mathrm{t}}<0\right)$

$$
\begin{aligned}
& -\epsilon_{\text {charge }} P_{t} \leq \text { psrc } M_{\text {bat }} \\
& S_{\text {bat }}=S_{\text {bat }}(t-1)
\end{aligned}
$$

2. ESS is discharging $\left(\mathrm{P}_{\mathrm{t}}>0\right)$

$$
P_{t} / \epsilon_{\text {discharge }} \leq \text { psrc } M_{\text {bat }}
$$

$$
S_{\text {bat }}=S_{\text {bat }}(t-1)-P_{t} \text { delta }_{t} / \epsilon_{\text {discharge }}
$$

3. ESS is stopped

$$
\begin{gathered}
S_{\text {bat }}=S_{\text {bat }}(t-1)-S_{\text {self }} \\
O b F_{x}=\operatorname{Min}_{x}\left[\sum_{l=o}^{t}\left(\operatorname{Cost}_{\text {bat }} x_{l}+\operatorname{Cost}_{R E, l} R E_{l}\right)\right] \\
O \text { ObF }_{x} \text { subject to }\left\{\begin{array}{c}
x(\text { intcon }) \\
A x \leq b \\
\text { Aeqx }=b e q \\
L x \leq x \leq U x
\end{array}\right.
\end{gathered}
$$

Equation (4),(5) and (6) showing the amount of power withdrawn or added to ESS power at any given time (10min).
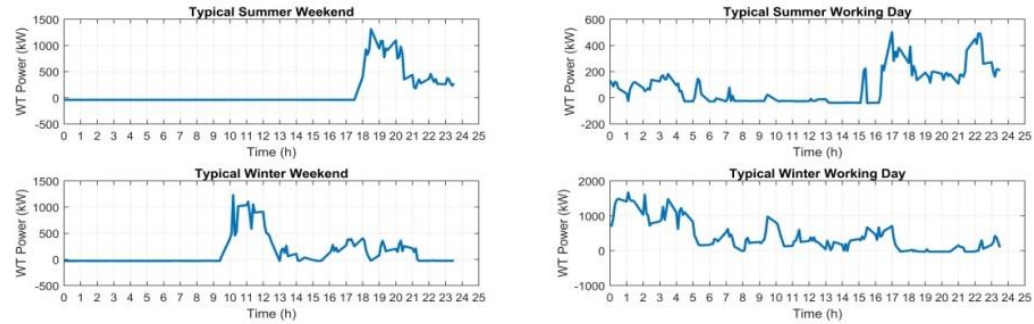

(a)
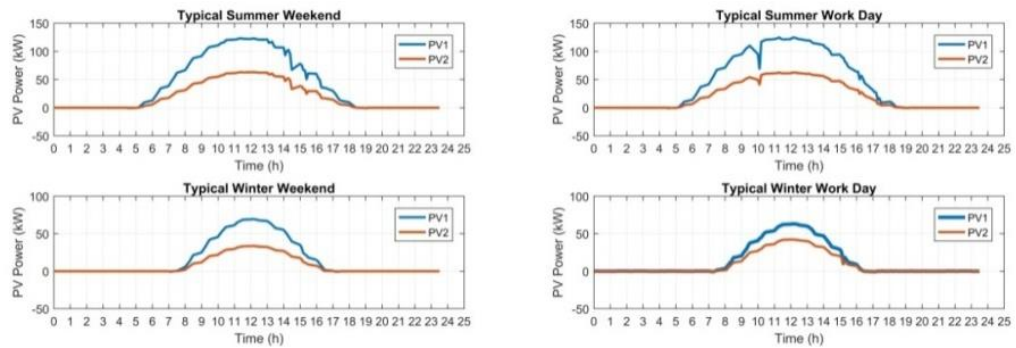

(b)
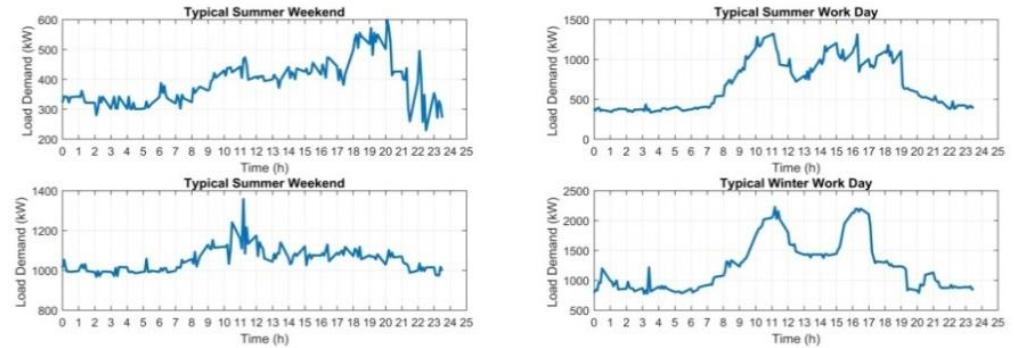

(c)

Fig. 6. Shows recorded of WT(a), PV (b) and Load Profile (c) Typical Summer weekend (8May2016) and Workday (10May2016), Winter Weekend (31Jan2016) and Workday (12Jan2016). 
Equations (7) and (8) are the objective function and resulted standard form to use in Matlab while solving the dispatch problem at every $10 \mathrm{~min}$ interval. It will minimize the cost function using all generation data at a particular time and local battery SOC status. The highest profit can be achieve between the light load and peak load periods, so the ESS charge operation through renewable generation must be scheduled on off peak time of the and discharge operation must be scheduled on peak time of the day.

In this case an aforementioned strategy plus some extra scenarios are solved by using constraints and limits. During the first peak time of the day if the battery if out of charge then the system will wait for the price to come down in mid peak hours then it will charge battery in those hours for the next peak hour's usage.

\subsection{Operational limits}

Constraints and limits are mentioned in (9)-(13), including ramping rate, unit capacity of individual units and power balancing .calculate these limits and bounds in the mentioned objective function in order to minimize the cost of usage of power for a particular generation scenario of the day.

$$
\begin{aligned}
& P_{\text {load }(l)}=P_{w(l)}+P_{p v(l)}+P_{b a t(l)} \\
& -P_{b a t}^{\text {rated }} \leq P_{\text {bat }(i)} \leq P_{b a t}^{\text {rated }}(1 \leq i \leq M) \\
& 0 \leq P_{w(i)} \leq P_{w}^{\max }(1 \leq i \leq M) \\
& 0 \leq P_{p v(i)} \leq P_{p v}^{\max }(1 \leq i \leq M) \\
& S_{b}^{\text {min }} \leq S_{b(i)} \leq S_{b}^{\text {max }}(1 \leq i \leq M)
\end{aligned}
$$

\section{Results and Discussion}

The energy management problem in Microgrid system can be defined as the multi objective optimization problem with desired constraint and bounds. The results shows the optimum generation points and the status of VRB for reducing the total cost while satisfying the bounds and constraint.

\subsection{Computer simulation}

Simulations have been carried out on Matlab on number of day scenarios including many summer and winter days. In Fig. 7 summer weekend generation point are given to the system and the resulting battery power is observed as the load on day time is supported by RE only and battery is almost empty at this point but after 23:00 the battery started charging using RE power. In the bottom case typical Winter workday is simulated which shows that battery is fully charged as the RE was sufficient enough to fulfil load demand whereas on peak supply power in peak hours battery almost empty and RE and grid was supporting the load at that point of time further battery started charging after 23:00 in off peak time.
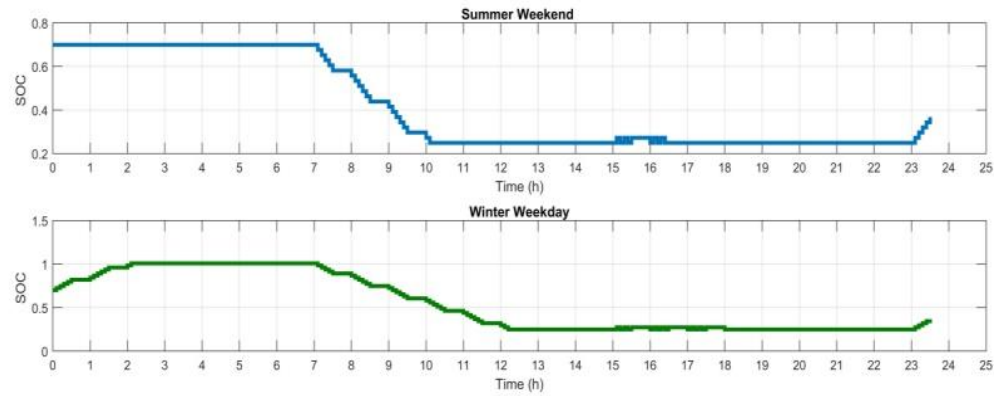

Fig. 7. Results of battery SOC on two typical days of the year. 


\subsection{Real time operation}

Fig 8. shows the snap shot of UI while working. Battery was charging in (8b) then on next refresh cycle is start discharging power as the RE power and grid prices changes then on next cycle as the RE went down it start charging again. In (8d), battery is charging through RE in off peak time of the day.

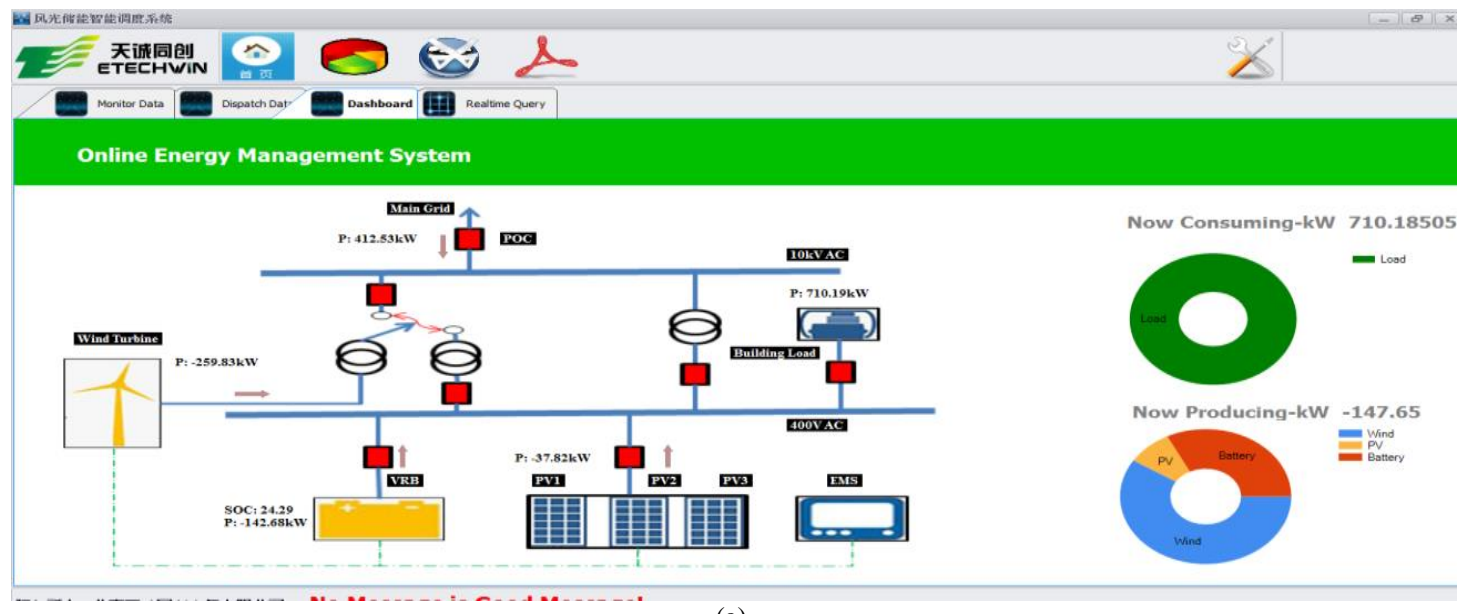

(a)

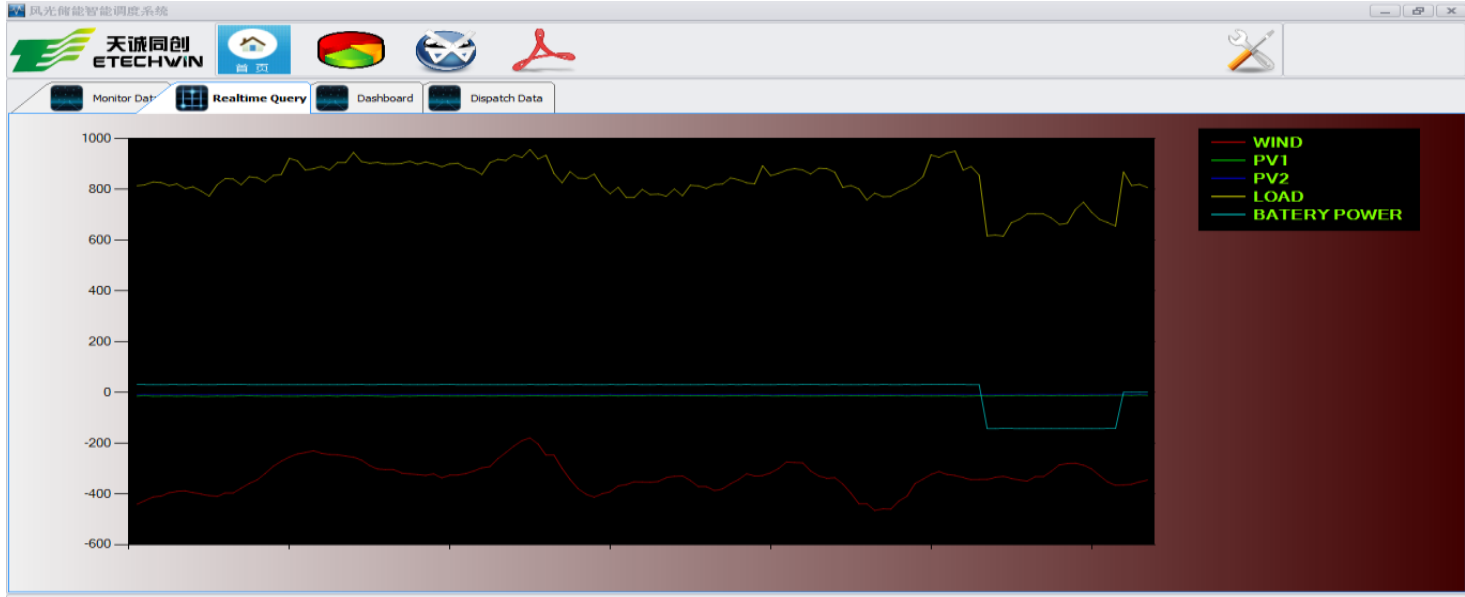

饭权所右@北京天诚同创电乞右限公司 No Message is Good Message!

(b)

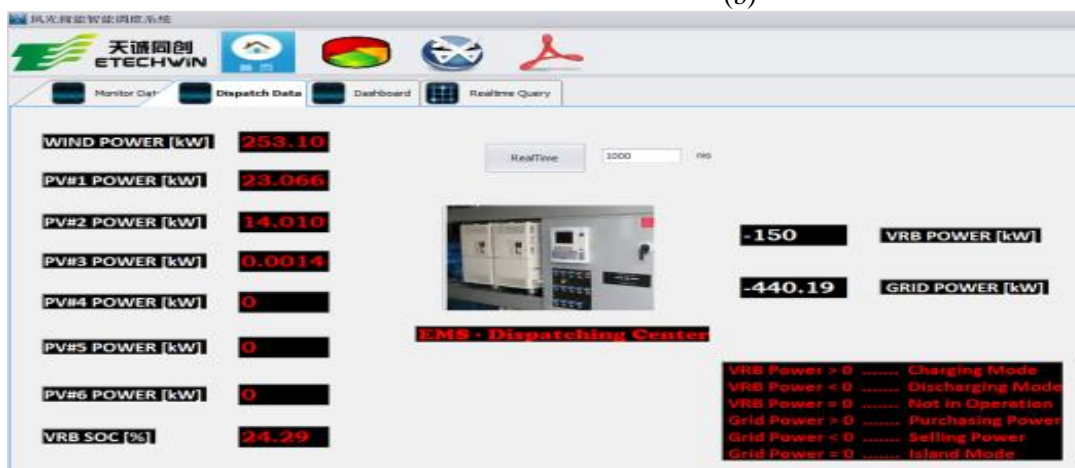




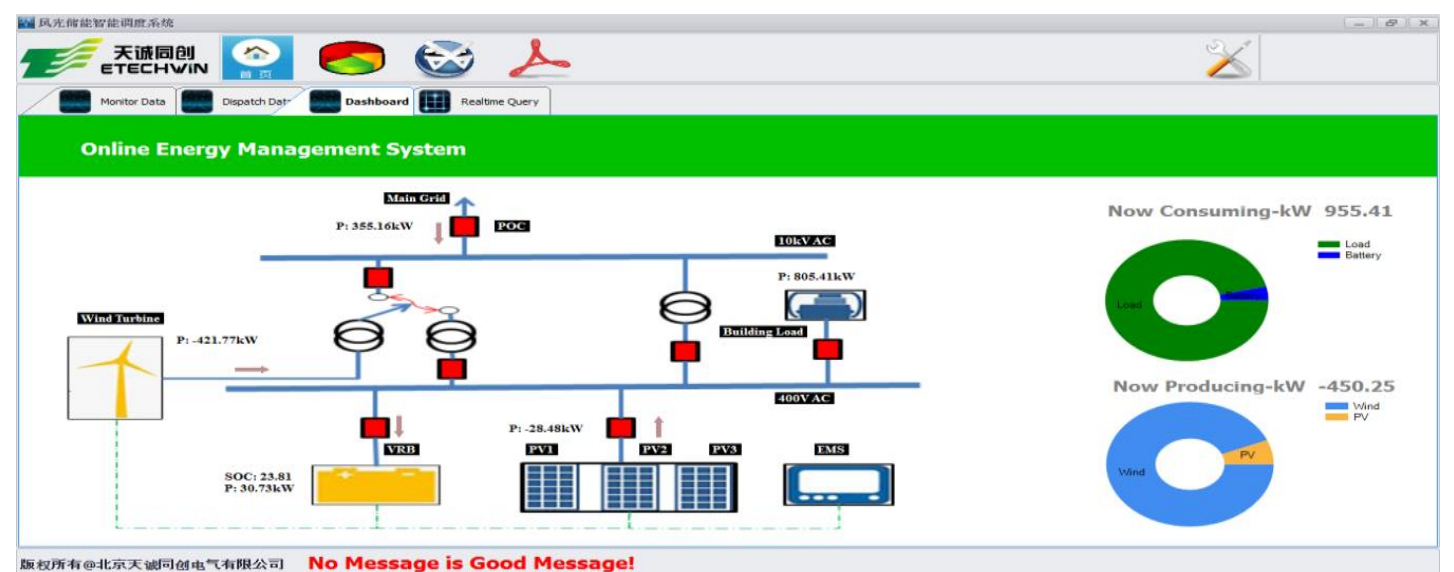

(d)

Fig. 8. User interface of System (a) battery is discharging (b) Battery switch to discharge state and next 10min stop (c)Updated data in real time dispatch (d) Battery is charging.

\section{Conclusion}

The paper proposed and implemented a battery management system for real time dispatch problem. This system used the real time power of Wind and PV and changes the battery on selected periods of time in a day based on the availability of the power then it used that stored power on peak time of the day in order to minimize the electricity purchase cost from the utility grid. System is tested on Goldwind Microgrid test bed in Beijing and the results of running the system are mentioned in the paper which validate the effectiveness of the implemented system. Future work will be focus on the implementation of Robust Energy management module using modified Neuro-fuzzy system developed herein.

\section{Acknowledgement}

The authors would like to acknowledge the tremendous help from Goldwind Technology, Beijing, North China Electric Power University Beijing and National University of Science and Technology, Islamabad for funding and moral support.

\section{References}

[1] Li X, Dong H, Lai X. Battery Energy Storage Station (BESS)-Based smoothing control of photovoltaic (PV) and wind power generation fluctuations. IEEE Transactions on Sustainable Energy, April 2013; 4(2).

[2] Cai H, Du W, Yu XP, Gao S, Littler T, Wang HF. Day-ahead optimal charging/discharging scheduling for electric vehicles in micro-grids. In: Proc. of 2nd IET Renewable Power Generation Conference, September 2013.

[3] Laudio AC, Rodrigo PB, Daniel EO, Ali MS, Amir HE, et al. Trends in microgrid control. IEEE Transactions on Smart Grid, July 2014; 5(4).

[4] Wang C, Yang X, Wu Z, Che Y, Guo L, Zhang S, Liu Y. A highly integrated and reconfigurable microgrid testbed with hybrid distributed energy sources. IEEE Transactions on Smart Grid, January 2016; 7(1).

[5] Chen C, Duan S, Cai T, Liu B, Hu G. Smart energy management system for optimal microgrid economic operation. IET Renew. Power Gener., 2011; 5(3):258-267.

[6] Kanzumba K. Optimal scheduled power flow for distributed photovoltaic/wind/diesel generators with battery storage system. IET Renew. Power Gener., 2015; 9(8):916-924.

[7] Nima N, Sajad NR. Optimal operation of distributed generations in micro-grids under uncertainties in load and renewable power generation using heuristic algorithm. IET Renewable Power Generation, 2015; 9(8):982-990.

[8] Katayoun R, Xu J, Rui Z. Real-Time energy storage management for renewable integration in microgrid: an off-line optimization approach. IEEE Transactions on Smart Grid, January 2015: 6(1).

[9] Magdi SM, Mohamed SUR, Fouad MALS. Review of microgrid architectures - a system of systems perspective. IET Renew. Power Gener., 2015; 9(8):1064-1078. 
[10] Shi W, Xie X, Chu CC, Gadh R. Distributed optimal energy management in microgrids. IEEE Transactions on Smart Grid, May 2015; 6(3).

[11] Zhou W, Lou C, Li Z, Lu L, Yang H. Current status of research on optimum sizing of stand-alone hybrid solar-wind power generation systems. Applied Energy, August 2009; 87(2010):380-389. 